\title{
A função das políticas compensatórias na reforma educacional da década de 1990, na Argentina*
}

\section{The function of compensatory politics on education reform of the decade of 1990 in Argentina}

\author{
Gladys Beatriz Barreyro**
}

A meu pai (in memoriam)

\begin{abstract}
RESUMO
Este trabalho discute o aparecimento e a função das políticas compensatórias na reforma educacional da década de 1990, durante o governo menemista, na Argentina, relacionadas diretamente com a reforma do Estado na época. A retórica destas políticas e da eqüidade encobria uma das características principais das políticas sociais que, na Argentina e na América Latina, tiveram o tratamento da pobreza: a focalização. Assim, as políticas compensatórias aplicadas na educação, especialmente com o Plano Social Educacional, permitiram a focalização, realizando despesas seletivas em obras e distribuição de materiais didáticos em algumas escolas, na tentativa de harmonizar os efeitos do ajuste estrutural e outorgar legitimidade à reforma educacional que se implementava.

Palavras-chave: educação argentina, reformas educacionais, políticas compensatórias.

* Agradeço a Andréa Barbosa Gouveia e a Silvia Beatriz Adoue pela revisão e

** Doutoranda no Programa de Pós-graduação em educação, na Faculdade de Educação da Universidade de São Paulo.gladysb@usp.br
\end{abstract} comentários ao texto. 


\begin{abstract}
This work discusses the emergence and the function of the compensatory politics in the education reform of the decade of 1990, during Menem government, in Argentina, which is directly related to State reform at that time. The rhetoric of the compensatory politics and equity covered-up one of the main characteristics of Argentinean, and Latin American, social politics and in Latin America had in relation to poverty treatment: focalization. In this way, the compensatory politics applied on education, mainly Education Social Plan, allowed a focused accomplishing to selective expenses, as buildings and distribution of didactic materials to some schools, which tried to harmonize the effects of structural adjustment and to grant legitimacy to education reform that was implemented.
\end{abstract}

Key-words: argentine education, education reforms, compensatory politics.

\title{
As políticas educacionais na Argentina, na década de 1990
}

Carlos Menem governou a Argentina durante uma década (1989-1999) na qual se produziu uma transformação no país. O presidente assumiu o poder antecipadamente em virtude de uma crise econômica e, com o apoio da bancada da oposição no poder legislativo, ${ }^{1}$ sancionou uma lei de reforma do Estado e uma lei de emergência econômica com as quais se instalou um modelo de ajuste que gerou uma mudança estrutural no país. "Menem e sua equipe de governo definiam a situação do país desde uma visão que

1 O governo de Alfonsín (partido Radical) tinha acabado antes do prazo devido ao que, na época, foi chamado de golpe de mercado, desestabilização produzida pelo sistema financeiro. Assim, as primeiras medidas de governo tiveram o apoio dos radicais, questão que permitiu realizar rapidamente as mudanças de orientação neoliberal.

2 Assim, em três anos, aplicou-se uma reforma que incluiu: a privatização da maior parte das empresas públicas, a abertura da economia, a reforma trabalhista anulando o conceito de estabilidade e a política de fixação de salários, a retração das políticas sociais e a privatização de suas funções. O modelo baseou-se em propostas de privatização, descentralização e desregulação, com o objetivo de reduzir o Estado, remetendo ao locus neoliberal do Estado mínimo. 
pode ser chamada de o discurso da urgência econômica" (SIDICARO, 1995). ${ }^{3}$ Os problemas argentinos eram econômicos e a solução devia ser econômica, por isso tanto a saúde quanto a educação, e a política em geral, eram tratados segundo critérios desse tipo, sem levar em conta sua função social. O novo peronismo ou menemismo também mudou sua relação histórica com os sindicatos, descartando os aumentos de salários e correlacionandoos com o critério da produtividade. Fez aliança com os empresários liberais, antigos inimigos do peronismo e realizou uma política pragmática baseada no predomínio de ações do poder executivo, sob a base de medidas provisórias, debilitando o poder legislativo que, aliás, ganhou um grande descrédito assim como a classe política que o compunha, devido ao seu espírito de corpo (PINTO, 1995).

O governo conseguiu controlar a inflação, manter uma situação de estabilidade (depois da hiperinflação e dos saques e arrastões de 1988/1989) baseada na Lei de Conversibilidade ( $1 \$=1 \mathrm{U} \$ \mathrm{~S})$, mas tal medida tornou a economia argentina muito dependente dos mercados internacionais e afetada pela crise mexicana de 1995, esta passou de um alto nível de crescimento para uma recessão, preparando o trágico desenlace de 2001, com a revolta popular e a queda do governo De La Rúa.

\section{A reforma educacional}

No âmbito educacional, houve muitos embates nesse período. Sob uma retórica de reforma e de transformação educativa, tentou-se adaptar a educação segundo os lineamentos neoliberais.

3 As versões do espanhol são da autora. 
O primeiro deles foi a descentralização administrativa ${ }^{4}$ que constituiu "um meio para obrigar às províncias a se enquadrar no ajuste fiscal (...) sob o pretexto de que o Estado, sustentando as escolas, favorece o "esbanjamento' provincial" (GRASSI et al., 1992, p. 4) e, entre outros efeitos, o processo de descentralização trouxe a diluição do conflito sindical, diversificando as negociações salariais em 24 províncias, tentando neutralizar assim a Confederação de Trabalhadores da Educação - CTERA. ${ }^{5}$

O Ministério da Educação deixou de gerir diretamente as escolas, mas manteve o controle. Segundo alguns autores (DUSSELL et. al., 1998, p. 146), houve "uma poderosa recentralização do Sistema Educacional, talvez maior que quando (o Ministério) administrava diretamente as escolas," conseguida por meio de quatro eixos ao redor dos quais foram organizadas as políticas educacionais (centralizadas) do período:

- estabelecimento dos Conteúdos Básicos Comuns, parâmetros sob os quais deviam se orientar as escolas, realizando as adequações regionais. Esse eixo propunha a atualização dos conteúdos às competências requeridas pela sociedade do conhecimento;

- avaliação do Sistema Educacional, realizada por meio dos Operativos Nacionais de Avaliação da Qualidade, provas ministradas aos alunos de algumas séries do ensino fundamental e de finalização do ensino médio. Dessa forma, e em estreita relação com o item anterior, o Ministério mantinha o controle dos resultados; tendo descentralizado a execução;

- capacitação docente: pela criação de uma Rede de Formação Docente Contínua que ministrava cursos pelo país. Os professores deviam se reciclar acumulando uma quantidade mínima de créditos sem os quais não poderiam continuar a exercer suas funções até o ano 2000. Este aspecto questionava o valor dos certificados no exercício da profissão e levou os professores a fazer os mais variados cursos;

4 A Lei n. 24049 transferiu as escolas de ensino médio (e outras) para as províncias (estados) completando um processo que tinha começado na ditadura militar (19761982). A rigor, a Constituição Argentina assinala que os estados devem prover a educação, mas isso não era cumprido já que era o Estado Nacional o responsável pela educação e ele criava escolas em todo o território. Os altos índices de alfabetização da população argentina devem-se a essa ingerência do Estado Nacional, que considerava a educação um dos eixos fundamentais para a construção da cidadania, já desde finais do século XIX.

5 Apesar dessa situação, os sindicatos docentes formam dos poucos que sistematicamente fizeram oposição ao governo. No final da década, utilizaram uma nova forma de protesto, a "carpa blanca", uma barraca montada em frente ao Congresso Nacional onde, em forma de rodízio, os professores faziam greve de fome. 
- a implementação de políticas compensatórias.

Aliás, criou-se o Conselho Federal de Cultura e Educação, constituído pelos representantes dos governos estaduais que deviam discutir políticas educacionais mas, na prática, aprovavam as políticas geradas no Ministério da Educação. Mediante a retórica da concertación (pacto, acordo) educacional, na verdade realizava uma falsificação do consenso (GENTILI, 2001).

\section{As políticas compensatórias}

As políticas compensatórias ${ }^{6}$ no âmbito educacional, e sua conseqüência, a implementação de políticas focalizadas, chegou ao Ministério da Educação argentino pela via latino-americana das recomendações de organismos internacionais, como a Cepal.

Historicamente, a concepção de compensação tinha origem na filosofia política liberal (VIEIRA, 1992) e as políticas compensatórias, no mundo anglo-saxão, foram as práticas de discriminação positiva como, por exemplo, a política de cotas para minorias em setores diversos da sociedade, nos Estados Unidos. Então, essas políticas tinham por objeto atacar as desigualdades estruturais e históricas que pretendiam e pretendem neutralizar.

Mas, as políticas compensatórias da década de 90 teriam outra finalidade, menos histórica e prolongada e mais imediata e assistencial; assim era explicitado pela Cepal que propunha uma evolução da compensação. Segundo esse organismo latinoamericano, ${ }^{7}$ as políticas compensatórias são uma solução para controlar os efeitos dos programas de ajuste que têm aumentado o nível de pobreza e mostrado a impossibilidade dos grupos sociais mais vulneráveis receberem benefícios essenciais, quando o Estado diminui o gasto público. Dessa forma, essas políticas têm por função controlar as situações de risco, os custos sociais do ajuste e a crise do emprego.

6 As temáticas desenvolvidas neste trabalho estão baseadas em aspectos parciais da minha dissertação de mestrado "Políticas educativas a fines del siglo XX en Argentina: un estudio del Plan Social Educativo" de la Maestría en Ciencias Sociales con mención en Educación da Facultad Latino-Americana de Ciencias Sociales (Flacso), sede Argentina.

7 RODRÍGUEZ NOBOA (1992) y (1991) 
Assim, admite a Cepal, estas políticas permitiriam "atenuar as maiores quedas produzidas tratando de revertê-las à situação social existente no início dos anos 80" (RODRÍGUEZ NOVOA, 1992). ${ }^{8}$

Embora as políticas compensatórias na sua concepção latino-americana aparecem relacionadas com políticas sociais diversas e não especificamente educacionais, o Ministério de Educação argentino, durante a década de 1990, levou essas definições para o âmbito educacional, criando também uma Direção Nacional de Programas Compensatórios. Mas, quais foram as medidas chamadas de políticas compensatórias durante o período citado, na educação argentina?

Certos programas que desenvolviam ações como:

- o envio de dinheiro às escolas para compra e entrega de materiais para os alunos (cadernos, lápis etc.) só para um universo de escolas selecionadas $;^{9}$

- o equipamento com livros só para o universo de escolas selecionadas;

- o envio de livros de primeira série (que não deviam ser devolvidos) para cada um dos alunos das escolas selecionadas;

- o pagamento das horas utilizadas pela participação em seminários de capacitação fora do horário escolar para os professores da $1^{\mathrm{a}}$ à $3^{\mathrm{a}}$ série só das escolas selecionadas;

- a construção de escolas cujo edifício era muito precário (chamadas de escolas rancho) dentro do universo de escolas selecionadas;

- a reforma ou construção parcial, segundo a necessidade determinada pela escola, no universo de escolas selecionadas;

- bolsas de estudos para o ensino médio, para alguns alunos;

- desenvolvimento de um projeto pedagógico específico para escolas rurais.

8 Também a retórica da compensação aparece em importantes documentos latino-americanos produzidos na década, tais como o Tratado de Assunção, que formaliza o Mercosul; a Declaração Final da Reunião de Presidentes Latino-americanos de 1992 e em Educação e Conhecimento: eixo da transformação produtiva com eqüidade, entre outros.

9 Ação semelhante com o Programa Dinheiro Direto na Escola realizado no Brasil durante o governo FHC e que é uma das recomendações do Banco Mundial para a Educação. Embora prática comum no Brasil e outros países, na Argentina não era um fato freqüente a entrega desses materiais por se considerar uma prática assistencialista. Costumava-se fazer tal distribuição nos sindicatos de algumas categorias para os filhos dos associados. Essa é uma das críticas feitas, na época. 
Ante tal diversidade de ações surgem algumas perguntas: é possível achar que a construção de uma escola com condições dignas seja uma política compensatória e não uma ação do Estado, decorrente do princípio constitucional de gratuidade e obrigatoriedade? O que isso compensa? O que nunca foi feito? Como considerar uma proposta diferente para um sistema de educação rural como política compensatória?

É possível analisar todas as ações sob o rótulo comum de políticas compensatórias? O que têm em comum?

Se for considerado que se tratam de ações tão aleatórias, é evidente que aquilo que as une é o fato de serem destinadas apenas para uma parte do sistema educacional, apenas para um universo de escolas selecionadas e não para a sua totalidade. Isto, na política social, é chamado de focalização.

A focalização é uma das características que, junto com a privatização e a descentralização, caracterizam as políticas sociais na América Latina depois do Consenso de Washington. Devido ao ajuste estrutural que os organismos internacionais recomendam para outorgar novos empréstimos, o gasto social diminui e então os governos latino-americanos são persuadidos a focalizar esse gasto nos mais pobres. ${ }^{10}$

Então, quem seriam estes focalizados?

\section{População alvo}

Afirmava-se nos documentos do Plano Social Educacional - PSE (política compensatória que juntava todas as ações acima citadas) que essas

10 CORAGGIO (1997), GRASSI; HINTZE et al. (1994), DRAIBE (1993), LAURELL (1995) e ISUANI (1992) destacam essas características para América Latina, especialmente Brasil, México e Argentina. A focalização, aliás, não perde atualidade haja vista recentemente a polêmica desatada na imprensa e no governo Lula sobre a focalização do gasto social: "Economista do PT faz críticas à proposta social de Palocci. Focalização de programas sociais e ênfase no ajuste fiscal, em vez do externo são principais alvos". (Folha de São Paulo, 21 abr. 2003). "Lula teve aula sobre plano social focalizado mexicano". (Folha de São Paulo, 27 abr. 2003). "Acordo com o FMI prevê focalização social". (Folha de São Paulo, 24 abr. 2003). 
políticas estavam destinadas aos pobres estruturais (16\% da população do país), mas, nos mesmos documentos, os dados mostravam que o público alvo era aquele correspondente aos novos pobres, chegando até $48 \%$ das escolas do país e a $35 \%$ dos alunos.

Esses novos pobres eram produto do ajuste que o próprio governo implementava, mas isso não era colocado nos documentos porque, na época, afirmava-se que os argentinos "viviam no primeiro mundo".

Então, é possível pensar que a obtenção de apoio político (para a reeleição presidencial na época) tanto quanto a contenção social (dado o aumento do desemprego) eram os objetivos dessas políticas no nível macro político. ${ }^{11}$

Uma das conseqüências da focalização foi a quebra da homogeneidade do sistema educacional argentino, distinguindo dois tipos de alunos: os $n e-$ cessitados e os competentes, gerando una subjetividade agradecida (DUSCHATZKY; REDONDO, 2000). Este assunto é muito relevante no interior da cultura argentina, porque a educação foi desde cedo um dos aspectos nos quais o Estado Nacional investiu na formação da cidadania. E, de fato, a sociedade argentina tinha um interessante nível de democratização. A educação argentina nunca antes havia diferenciado os alunos, muito pelo contrário, seu discurso e as práticas correntes tendiam à homogeneização. Embora existissem divergências no interior do sistema educacional, especialmente quanto a resultados, o alto índice de alfabetização alcançado no século XX, baseado na escola pública, gratuita e obrigatória, mostra essa situação. $\mathrm{O}$ fato de estabelecer uma diferenciação entre população necessitada e não necessitada, além de quebrar a utopia republicana da igualdade, gerou também a naturalização da pobreza, decretando sua existência como um elemento permanente da sociedade que precisará de ajuda daqui para frente. ${ }^{12}$

11 Essa afirmação foi comprovada numa pequena cidade da Província de Santa Fe, na qual fiz trabalho de campo. Ali, todas as escolas públicas estavam incluídas no plano, embora os dados estatísticos oficiais assinalassem que $13,9 \%$ da população era considerada pobre estruturalmente. Cabe assinalar que na Argentina até a classe média utiliza a escola pública.

12 Talvez seja impossível explicar melhor esta afirmação em tão poucas linhas para uma sociedade tão diferente quanto a brasileira. Ver PUIGGRós (1991). 


\section{Distribuição de livros}

Uma das ações que gerou maior investimento no PSE foi a distribuição de livros (para alunos da primeira série) e dinheiro (para a compra de materiais didáticos para os alunos) nas escolas selecionadas. ${ }^{13}$

Pretende-se problematizar essa prática no contexto em que foi realizada. Na retórica da compensação, os livros parecem ligados mecanicamente à qualidade da educação sem levar em conta que um só elemento não melhora a qualidade. Assim, nos documentos oficiais assinala-se: "ninguém duvida, hoje em dia, que além dos avanços tecnológicos permanentes, os livros continuam a ser um dos materiais mais eficazes para desenvolver as capacidades das crianças." " Mas também ninguém duvida que (para mostrar só um exemplo) aumentar as horas de aula melhora a educação. E também alguns duvidam dos livros (como estratégia única): "se levamos em conta a pesquisa empírica como parâmetro para dirimir a validez de determinadas opções de política, existem estudos - alguns promovidos pelo próprio Banco Mundial - que contradizem ou pelo menos matizam as afirmações no que diz respeito ao livro de texto.” (TORRES, 1997, p. 113) Então, a eleição desta estratégia ao invés de outras ou complementariamente com outras, parece ter origem no fato de que o gasto com livros é um dos itens priorizados pelas recomendações do Banco Mundial. Ou seja, o Banco Mundial acha que é melhor gastar em livros, então - devido as condicionalidades que os empréstimos dos organismos internacionais impõem aos países com dívida externa - é melhor gastar em livros do que em salários dos professores ou aumentar as horas de aula. E esse não é um argumento retórico, porque a política compensatória PSE era a contraprestação que o Estado argentino devia fazer para receber um empréstimo: $^{15}$

Ou seja, o BID entregava dinheiro para o Programa de Reformas e Investimento no setor Educação (PRISE), se o Estado argentino, como contraprestação, investia o dinheiro de seu próprio orçamento em livros. Então, tomava-se esta atitude porque havia sido avaliado que era a melhor

13 Na Argentina não existia nenhuma política de livro didático.

14 Disponível em: <www.goplher.mcye.gov.ar> Acesso em: 25 maio 99.

15 Resolução n. 561 Ministério da Educação, 17 mar. 1997. 
forma de melhorar a qualidade ou porque assim podia-se conseguir dinheiro? O que poderia ter acontecido com o empréstimo se o governo tivesse decidido investir em melhores salários?

Além disso, os livros têm uma visibilidade legitimadora também para os pais já que 20.000.000 de livros (ZONA EDUCATIVA, 1999, p. 33) são percebidos. Ademais, todos gostam de que as escolas tenham livros e que os filhos estudem com eles, mas sabe-se também que outras coisas são necessárias e não apenas os livros. ${ }^{16}$

Em consequiência, a entrega de livros e materiais estava relacionada com as orientações do Banco Mundial sobre "em que é ou não possível gastar" na educação latino-americana, critério aplicado na reforma educacional argentina que congelava salários dos professores, mas tinha fundos para as provas de avaliação e para as políticas compensatórias. Mas esta opção (neste caso de livros), além do mais, mexia com a história do partido no governo. Ao que AUYERO (1999b) chama memória distribucionista, nos setores populares argentinos, nos descendentes dos que tinham vivido durante a década peronista (1945-1955) existe um imaginário da distribuição de bens relacionado com Evita Perón que, sem dúvida, o menemismo tentou ativar. ${ }^{17}$ Então, tanto na distribuição de bens quanto na construção de escolas (também realizadas pelo PSE), pretendia-se acessar a memória peronista em Estados onde a última construção de escolas foi, precisamente, na década de 1940 !

16 Embora se apresente aqui apenas a análise do caso dos livros, outras ações como a entrega de materiais ou o envio de dinheiro direto na escola também são sugestões dos relatórios do Banco Mundial para a educação.

17 O peronismo na década 1945-1955 foi um governo de implantação de direitos universais e duradouros no qual os componentes assistenciais não foram preponderantes ,mas complementares. Foi a esposa do presidente, Eva Perón, mediante a Fundação Eva Perón quem realizou as tarefas assistenciais. Suas atividades centraram-se na distribuição de subsídios e bens materiais de diversos tipos (entre os quais livros escolares e roupas) As atividades eram justificadas como transitórias e subsidiárias até quando fosse alcançada a justiça social (TENTI, 1989; ISUANI, 1989). O menemismo, pelo contrário, apenas realizou tarefas assistenciais tirando os direitos sociais já adquiridos 


\section{Gasto seletivo}

Conforme afirmado anteriormente, o Estado argentino estava realizando um ajuste educacional, com o qual pretendia priorizar a educação, realizando uma reforma. Eram implementadas algumas ações destinadas à população mais afetada pelo ajuste, chamadas de políticas compensatórias. Algumas delas: a distribuição de livros e materiais aos alunos, eram ações assistenciais, porém muitas outras na realidade eram gastos correntes, ou seja, gastos que tinham que ser feitos para a prestação do serviço educacional. Assim, a manutenção de edifícios, o equipamento tecnológico, científico e das bibliotecas são necessários para cumprir com a função do Estado no que diz respeito à educação. Mas, como o investimento básico neste sentido tinha sumido na década, a estratégia do PSE consistiu em realizar a manutenção básica, apenas em algumas escolas, apresentando-a como extraordinária. Aliás, o fato de atingir apenas algumas escolas permitia maior destaque e, também, consolidava na prática a subsidiariedade do Estado na manutenção da educação, porque as escolas não incluídas deviam procurar seus recursos na comunidade. Além disso, as estratégias de chegada que foram desenvolvidas permitiram, ressaltar mais esse gasto seletivo com o objetivo de buscar legitimação e apoio político.

\section{Estratégias de chegada}

Os materiais enviados pelo PSE criaram um canal direto de comunicação entre o governo - Presidência da Nação - e as escolas, apesar da recente descentralização do sistema educacional. Assim, todos os elementos deste plano e especialmente os materiais didáticos (cadernos, folhas etc.) possuíam uma iconografia própria: uma pomba e a legenda: "Presidência da Nação. Plano Social Educacional," nas cores azul e branco, cores da bandeira nacional e do partido peronista.

Reforçando essa relação presidência-escolas, a chegada dos livros às instituição era um ritual pautado nos documentos do PSE: "A entrega dos 
livros de texto aos alunos será realizada durante a Festa Institucional pública na qual participe toda a Comunidade da escola:"18 Um detalhe excessivamente centralizado para um governo que acabava de propor a autonomia dessas mesmas escolas.

Assim, a presidência (e o presidente) assegurava sua chegada sem que o PSE pudesse passar desapercebido.

As diversas ações, desse modo, estavam dirigidas especificamente a diferentes destinatários: professores (capacitação), pais e alunos (bolsas, livros, materiais) resultando, em consequiência, serem muito abrangentes na sua busca de apoio.

\section{Em síntese}

A retórica das políticas compensatórias foi usada como legitimação da reforma educacional realizada no contexto de ajuste estrutural do governo de Menem, na Argentina, na década de 90. As políticas compensatórias envolviam uma das características fundamentais das políticas sociais para o combate à pobreza na América Latina: a focalização, priorizando como população alvo os setores sociais mais atingidos pelas conseqüências do ajuste.

Tais políticas compensatórias na educação e, especialmente a aplicação do Plano Social Educacional, permitiram focalizar diversas ações num universo restrito de escolas, adquirindo assim maior destaque. As ações realizadas não tinham uma clara justificativa, mas concordavam com as recomendações do Banco Mundial para a educação e possuíam estratégias de chegada aos destinatários que as ressaltavam.

Neste artigo, foram empregados os termos retórica da compensação por se tratar de um discurso que foi utilizado para destacar e justificar tanto práticas assistenciais quanto ações que, mormente, apresentavam um gasto público normal como se fosse uma situação extraordinária. Não que essas ações não tenham sido realizadas, senão envolvidas num discurso com fins específicos. 
A retórica da compensação e suas ações, dessa forma, resultaram eficazes para legitimar a reforma educacional, somar apoio político e manter o controle social.

\section{REFERÊNCIAS}

AUYERO, J. Re-membering Peronism: An ethnographic Account of the Relational Character of Political Memory. Qualitative Sociology, v. 22, n. 4, 1999.

BANCO MUNDIAL. Prioridades y estrategias para la educación. Washington. WB. 1996.

. El financiamiento de la educación en los países en desarrollo. Opciones de política. Washington. WB, 1986.

BARREYRO, G. Políticas educativas en la Argentina a fines del siglo XX: un estudio del Plan Social Educativo. Buenos Aires, 2001. Tesis (Maestría) - Facultad Latinoamericana de Ciencias Sociales (FLACSO), sede Argentina.

CEPAL. Educación y conocimiento. Eje de la transformación productiva con equidad. Santiago de Chile. 1992.

CORAGGIO, J. L. Las propuestas del Banco Mundial para la educación. La educación según el Banco Mundial. Un análisis de sus propuestas y métodos. Buenos Aires: Miño y Dávila, 1997. p. 11-68.

DRAIBE, S. As políticas sociais no neoliberalismo. Revista da USP. Dossié LiberalismoNeoliberalismo, São Paulo, n. 17, p. 86-101, 1993.

DUSCHATZKY, S.; REDONDO, P. El plan social educativo o los indicios de ruptura de las políticas públicas. In: DUSCHATZKY, S. (Comp.). Tutelados y asistidos: programas sociales, políticas públicas y subjetividad. Buenos Aires: Paidós, 2000. p. 121-185.

DUSSEL, I.; TIRAMONTI, G.; BIRGIN, A. Hacia una nueva cartografía de la reforma curricular: Reflexiones a partir de la descentralización educativa argentina. Revista de Estudios del Currículo, v. 1, n. 2, p. 132-158, 1998.

GENTILI, P. A falsificação do consenso. Simulacro e imposição na reforma educacional do neoliberalismo. 2. ed. Petrópolis: Vozes, 2001.

GRASSI, E.; HINTZE, S.; NEUFELD, M. Políticas sociales. Crisis y Ajuste Estructural. Buenos Aires: Espacio Editorial, 1994.

ISUANI, E. Política social y dinámica política en América Latina. ¿Nuevas respuestas 
para viejos problemas? Desarrollo Económico. Revista de Ciencias Sociales, Buenos Aires: Ides, v. 32, n. 125, p. 107-118, 1992. . Estado democrático y política social. Buenos Aires: Eudeba, 1989.

LAURELL, A. C. Avançando em direção ao passado: a política social do neoliberalismo. In: LAURELL, A. C. (Org.). Estado e políticas sociais no neoliberalismo. São Paulo: Cortez, 1995. p. 151-178.

MINUJIN, A. et al. Cuesta abajo. Los nuevos pobres: efectos de la crisis en la sociedad argentina. Buenos Aires:Unicef/Losada, 1991.

PUIGGRÓS, A. (Org.). Sociedad civil y estado en los orígenes del sistema educativo argentino. Buenos Aires: Galerna, 1991. p. 309-337.

RODRIGUEZ NOBOA, P. Renovadas orientaciones y tendencias de los programas de compensación social en la región. In: CEPAL, CONFERENCIA REGIONAL SOBRE LA POBREZA EN AMÉRICA LATINA Y EL CARIBE, 3., 1992, Santiago de Chile. Anais... Santiago de Chile, 1992.

. La selectividad como eje de las políticas sociales. Revista de la CEPAL, Santiago de Chile, n. 44, p. 56-62. 1991.

SIDICARO, R. Poder político, liberalismo económico y sectores populares en la Argentina 1989-1995. In: BORON, A. et al. Peronismo y menemismo. Avatares del populismo en la Argentina. Buenos Aires: El cielo por asalto, 1995.

SOJO, A. Naturaleza y selectividad de la política social. Revista de la CEPAL, Santiago de Chile, n. 41, p.183-199, 1990.

TENTI, E. Estado y pobreza. Estrategias típicas de intervención 1. Buenos Aires: Centro Editor de América Latina, 1989.

TIRAMONTI, G. O cenário político e educacional dos anos 90: a nova fragmentação. Cadernos de Pesquisa, São Paulo: Fundação Carlos Chagas, n. 100, p. 79-91, 1997 a.

. Los imperativos de las políticas educativas de los 90. Revista da Faculdade de Educação, USP-SP, v. 23, n. 1-2, p. 49-69, 1997 b.

TORRES, R. M. ¿Mejorar la calidad de la educación básica? Las estrategias del Banco Mundial. La educación según el Banco Mundial. Un análisis de sus propuestas y métodos. Buenos Aires: Miño y Dávila, 1997. p. 71-161.

VIEIRA, E. Democracia e Política social. São Paulo: Cortez-Autores Asociados, 1992. 


\section{DOCUMENTOS}

- Ministerio de Cultura y Educación (MCYE). Resolución Ministerial n. 561, 17 abr. 1997.

- Consejo Federal de Cultura y Educación (CFCYE). Resolución n. 29/93. Disponível em: <http://www.me.gov.ar>

- CFCYE. Resolución n. 33/93. Disponível em: 〈www.me.gov.ar>

- CFCYE. Resolución n. 56/93. Disponível em: 〈www.me.gov.ar>

- Ley Federal de Educación, n. 24.195. Disponível em: 〈www.me.gov.ar〉

- Pacto Federal Educativo Disponível em: 〈www.me.gov.ar>

- MCYE.(1995) Contenidos Básicos Comunes para la Educación General Básica.

- MCYE. (1992) Plan Trienal para el Sector Educación en el Contexto del Mercosur. Serie Perspectiva Internacional. Bs.As.

- Declaración Mundial de Educación para todos, In: MCYE. (1998) Calidad, equidad y Pertinencia. Documentos de referencia, Seminario Regional de Programas Compensatorios en Educación. Bs.As.

- Declaración de la Cumbre de las Américas (íd).

- MCYE.(1993) Revista “Zona Educativa”. n. 3. Disponível em: 〈www.me.gov.ar>

- MCYE.(1999a) Revista “Zona Educativa”. n. 35. Disponível em: 〈www.me.gov.ar〉

- MCYE (1999b) Enseñar el futuro. Disponível em: 〈www.me.gov.ar/EEF>

- MCYE (1999c) La educación argentina en la sociedad del conocimiento. Disponível em: <www.zona.mcye.gov.ar/EAC/SPA/home.html>

- MCYE (1998). Mejor Educación para todos. Programas compensatorios en Educación de la República Argentina:1993-1998. 187 p.

- PSE/FUNDARED (1999) Evaluación del Plan Social Educativo.-

- PSE/FUNDARED (1999) Informe sobre repitencia. Primer informe. Fase extensiva. Datos sobre la muestra de escuelas de proyecto 1. Documento de distribución interna. Mimeog.

- PSE (1998) Sistematización de los resultados del operativo de seguimiento realizado en el año 1997 en 877 escuelas del proyecto "Mejoramiento de la calidad de la educación en escuelas del nivel inicial y de la educación general básica”. Mimeog. 
- El Plan Social Educativo Disponível em: <www.gopher.mcye.gov.ar:70/00/plansoc/ plan> Acesso em: 25 maio 99.

- Criterios fundamentales de diseño de las acciones complementarias (sic) en educación. Disponível em: <www.mcye.gov.ar/pl.soc> Acesso em: 25 maio 2000.

- Cuatro años de políticas compensatorias. Disponível em: 〈www.mcye.gov.ar/pl.soc〉 Acesso em: 25 maio 99.

- Plan social educativo. Disponível em: <www.mcye.gov.ar/pl.soc> Acesso em: 25 maio 99.

- Presentación general. Programa I. Mejor educación para todos. (mimeog., s/f, circa 1995) $24 \mathrm{p}$.

- Para trabajar mejor. Manual Operativo 1995. Nivel primario.(1995) Proyecto 1, Programa I. 121 páginas.

Texto recebido em 10 ago. 2003

Texto aprovado em 03 out. 2003 